\title{
Fractures of the femoral shaft in children
}

\author{
H. NeVile Burwell \\ Ch.M., F.R.C.S.
}

The General Hospital at Batley, Yorkshire

\begin{abstract}
Summary
A series of 133 fractures of the shaft of the femur in children (during the first 12 years) is discussed. The injury is much more common in boys. The highest incidence is in 3-year-old children.

A gentle reduction is desirable and anaesthesia is rarely necessary.

In the age group under consideration $\frac{1}{2}$ in. of shortening in reduction is desirable; angulation should be avoided.

Initial immobilization in younger children on Bryant's traction and in older children on a Thomas' splint has been found satisfactory.

The application of a plaster spica after 2 or 3 weeks allows the child to return home and in this way saves hospital beds. Physiotherapy is not required.

Complications should be avoided particularly with good nursing care but regular observation for vascular impairment (particularly after traffic accidents) is necessary.

The management of this injury is usually uncomplicated and provides good experience for junior medical staff under supervision.
\end{abstract}

\section{Introduction}

The management of most fractures in children is not difficult since non-union is rare, physical rehabilitation is unnecessary, and deformity, unless severe, is often overcome by remodelling of the bone. The present paper concerns fractures of the femoral shaft in the first 12 years of life as seen over a period of 14 years in an accident service provided for an urban population of about 170,000 . No innovations are claimed but on analysis certain points emerged which were considered to be worthy of comment. The treatment has been standardized so as to reduce the time spent in hospital and to avoid unnecessary attendance in the out-patient clinic.

\section{Incidence}

There were 130 children in the series, of whom three had fractures in both femora, making 133 fractures in all. Over the period of 14 years (1954 67) an average of 9.3 children was, therefore, admitted each year (range 6-15). This is not a large number when compared with the annual admission of about seventy-five of these injuries to the Toronto Children's Hospital as reported by Thomson \& Mahoney (1951). Toronto at that time had a population of 651,000 which should have resulted in only about thirty-seven of these fractures annually if compared with the incidence in the present paper; it would seem that the difference is related to the larger number of traffic accidents occurring in the Canadian city.

\section{Aetiology}

Clark (1926) and Conwell (1929) reported that traffic accidents were responsible for 46 and $42 \%$, respectively, in their series of fractures of the femur in children. In the present series only $26 \%$ were caused by traffic accidents. This lower incidence may be related to the absence of any high-speed roads in the urban area in which the injuries occurred. Many of the fractures in this series resulted from relatively minor trauma such as a fall at play.

\section{Age and sex}

The age incidence in this series is shown in Fig. 1. It is of interest that the frequency rises steeply to a peak at 3 years after which there is a steady decline. It is also seen that the fracture is much more common in boys of whom there were $100(77 \%)$ with only thirty girls (23\%). Bloch (1922) reported an almost identical sex incidence in a large series (539 fractures)boys $76 \%$ and girls $24 \%$. The marked sex difference becomes established in the 3rd year and persists in subsequent age groups. 


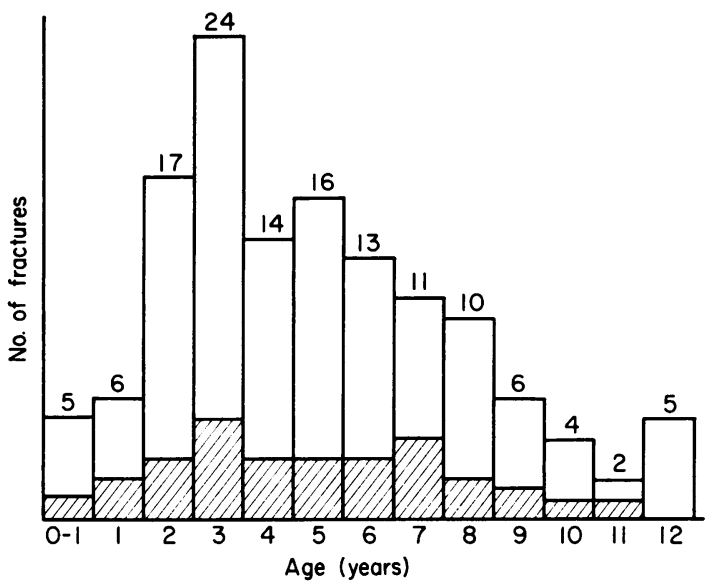

Fig. 1. Distribution of patients according to sex and age. Open columns, boys; hatched columns, girls.

\section{Type and level of fracture}

Sixty-eight per cent of the fractures were found to be spiral or oblique, $30 \%$ were transverse and only $2 \%$ were greenstick. Other writers have reported that transverse fractures are the most common (Clark, 1926; Conwell, 1929) but this may be related to a higher incidence of road accidents in their series. Thus, as stated above, Clark (1926) had $46 \%$ road accidents in his series whereas in the present series eighteen of the thirty-four road accidents (more than half) resulted in the less common transverse fracture.

There is agreement that the most frequent level of injury is the middle of the shaft. In the present series the incidence of fractures at the different levels is shown in Fig. 2. These findings are consistent with those of Blount (1955) although Conwell (1929) in a series of eighty-nine fractures reports a somewhat lower incidence at mid-shaft and higher in the lower shaft.

\section{Side}

Other writers have commented on a higher incidence of fractures on the left (Clark, 1926; Conwell, 1929) but this finding was not confirmed in the present series-sixty-three left, sixty-four right and three both femora.

\section{Reduction of the fracture}

\section{(a) Closed reduction}

Although earlier writers such as Speed (1921) and Burdick \& Siris (1923) advocated routine reduction by traction under general anaesthesia and this method was supported by Dameron \& Thompson as recently as 1959 , the present view is that full reduction is undesirable because of subsequent

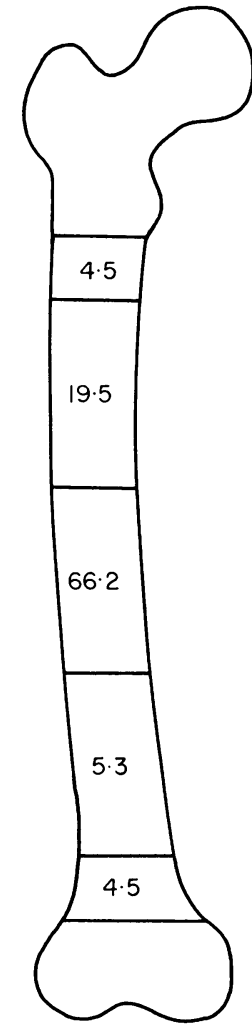

FIG. 2. Incidence of fractures according to level.

stimulation of growth of the injured bone. In the present series the aim has been to leave half an inch of shortening without any angulation or rotation. This is usually achieved spontaneously when Bryant's traction is applied and only occasionally when applying fixed traction on a Thomas' splint has general anaesthesia been used.

\section{(b) Open reduction}

Open operation is rarely indicated in the agegroup under consideration; it was used only once in the present series to achieve stability in a child with fractures of both femora and the left tibia and fibula (Fig. 3). It is seen that the length of the right femur was fully restored after closed reduction so that there was no contra-indication to full reduction at operation in the left femur which could otherwise have resulted in ultimate inequality in the lengths of the limbs.

Although earlier writers (Kidner \& Lakoff, 1922; Clark, 1926) considered that open operation should be done for muscle interposition the present view is that operation is unnecessary (Blount, 1955; Dameron \& Thompson, 1959). It is also the present writer's experience that spontaneous union 

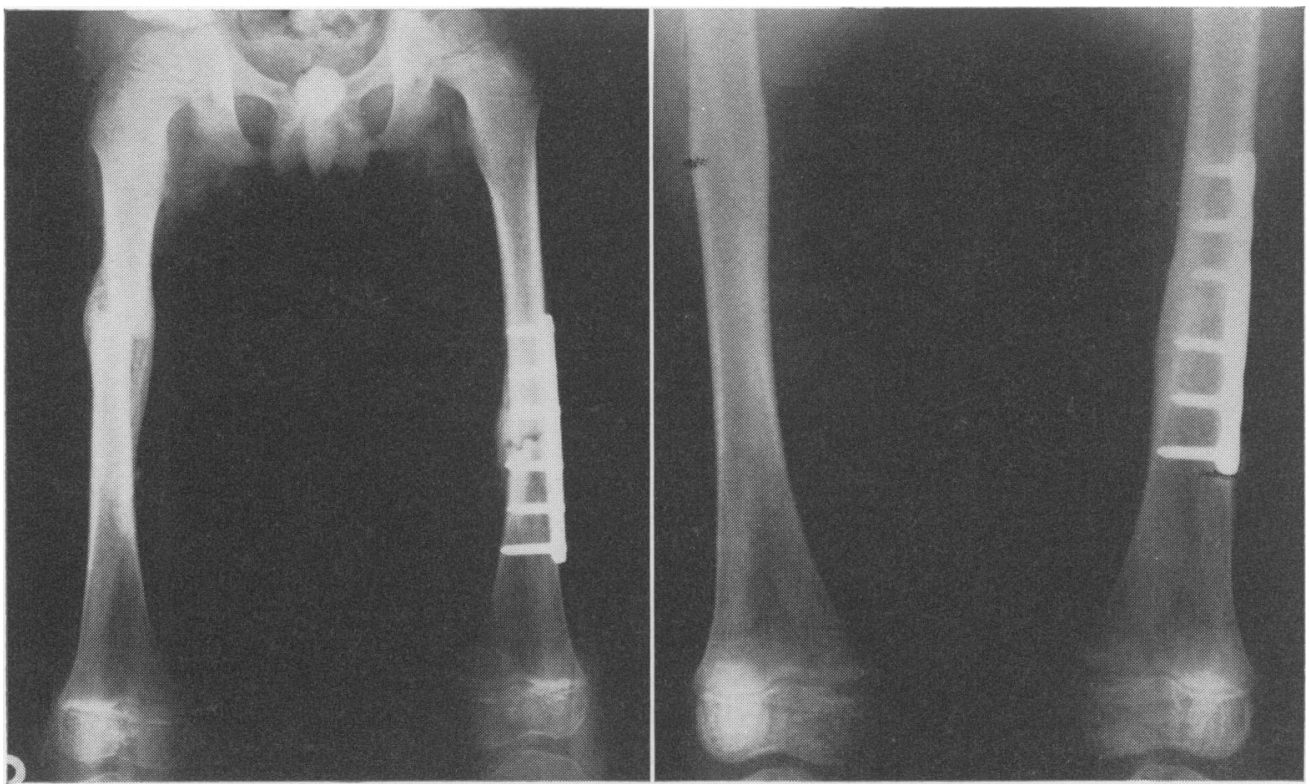

Fig. 3. Fractures of both femora: (left) 2 months_and (right) 8 months after plating of left femur.

is achieved with certainty and in the absence of any significant delay; this is in keeping with the high osteogenic potential of growing children. There was no instance of non-union in the present series. Blount (1955) observed that non-union occurred only if operation were done stating that the plates were prone to break even with the limb supported in a plaster cast and that weak callus was formed. The present writer would agree with this only if the plating were insecure which should, however, be avoided in fracture treatment (Burwell \& Charnley, 1964). The only fracture treated by open operation in this series (Fig. 3) is seen to be fixed securely with a strong plate and six screws; union occurred in the normal period. Blount also said that plates ought to be removed; this should, however, rarely be necessary if an inert metal such as the cobaltchromium alloy, vitallium, is used.

\section{Splintage}

The method of 'gallows traction' described by Bryant (1876) was used as the initial form of splintage in most of the sixty-six fractures in children who were younger than 5 years. In older children it is found that the reduction is frequently unsatisfactory and that the strapping extensions may not remain secure. It is important not to use this method in the presence of surgical shock because of the risk of vascular impairment from the acute elevation of the lower limbs (Dameron \& Thompson, 1959). In this series Elastoplast skin extension plasters carefully supported with crêpe bandages

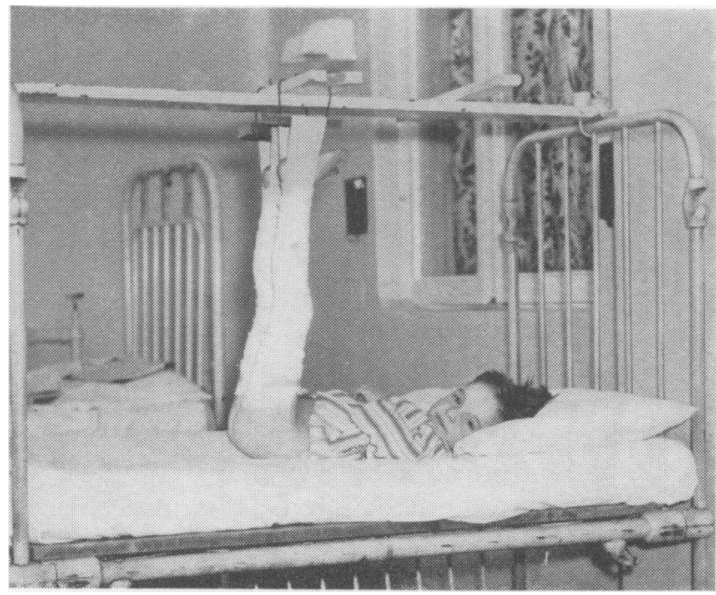

FIG. 4. Bryant's traction.

were used and combined with fixed traction to an overhead wooden frame (Fig. 4). No pressure sores or any instance of circulatory embarrassment occurred.

For older children in this series fixed traction (using skin extensions) on a Thomas' splint was used. A few patients required general anaesthesia for satisfactory application of the splint. Skeletal traction was not found necessary in the present series and would seem only to be indicated when wounds prevent the use of skin traction or in neglected fractures. Both Eikenbary \& LeCocq 


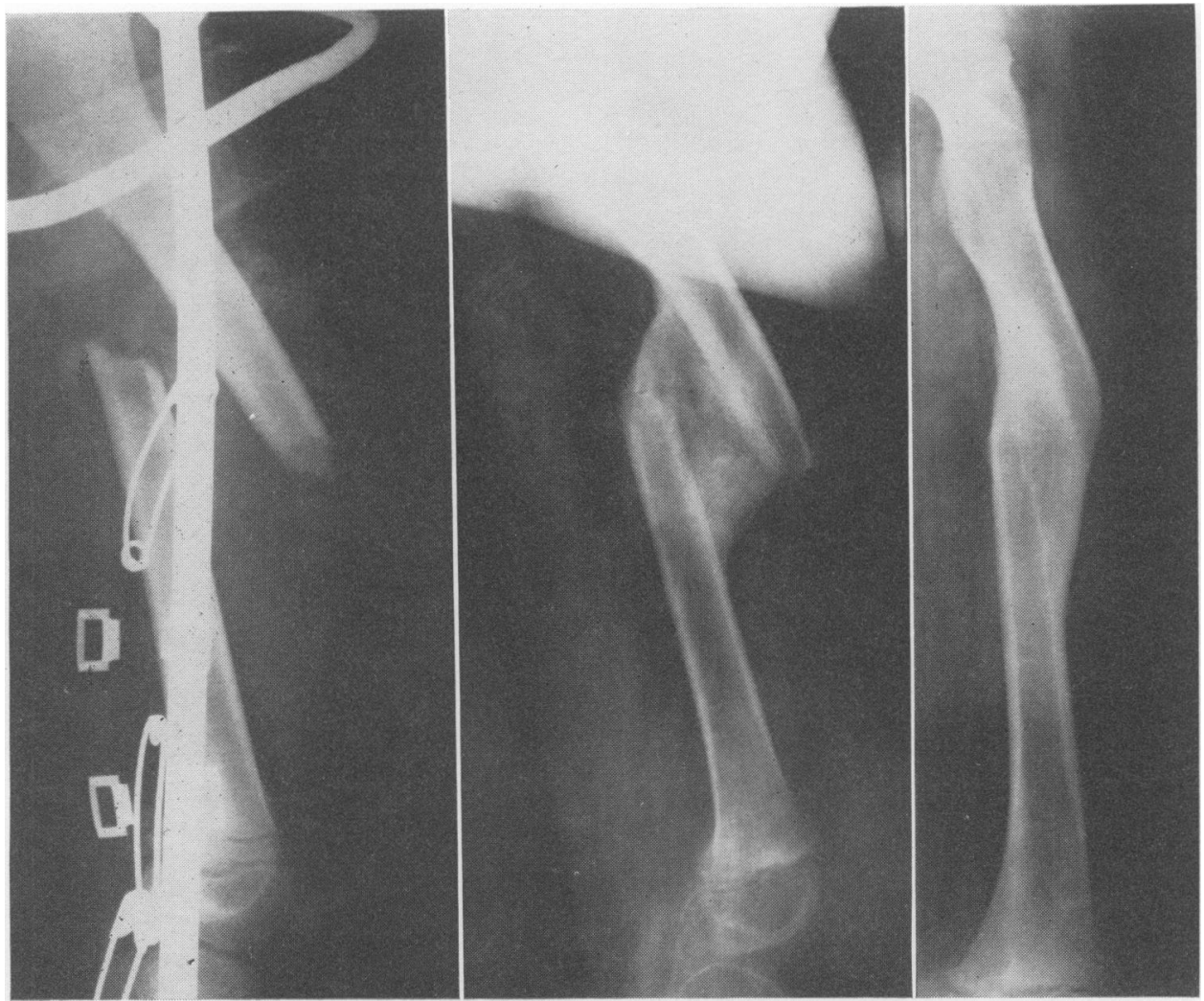

Fig. 5. Severe head injury prevented reduction of fracture. Shortening and displacement overcome in 1 year.

(1932) and Blount (1955) used the traction method of Russell (1924) for these injuries but the present writer has found the Thomas' splint more satisfactory for children.

Earlier writers e.g. Cushing (1898), Cole (1922) and Johnston (1925) had differing views on the use of plaster spicas as the primary splintage of femoral fractures in children. For undisplaced fractures it clearly provides good splintage. For displaced fractures it is the present writer's experience that the small amount of desirable shortening cannot be regularly obtained with this form of splintage and there is a risk of angulation occurring in the cast at this early stage; a further disadvantage is that anaesthesia is necessary for its application shortly after the injury. The use of a plaster spica is, however, an important 'hospital bed-saver' if it is applied 2 or 3 weeks after the accident, depending on the age of the patient, at a time when further shortening will not occur and early callus formation is present. In this series unilateral well-fitting spicas, including the foot, were applied by an experienced technician, without anaesthesia, and no instance of subsequent angulation at the fracture was found. This delayed application of a spica was recom- mended nearly 50 years ago by Cole (1922) and later by Derian \& Thompson (1961). The child may then return home and presents no nursing problem, even to an inadequate mother, since the child's level of activity, in bed or on the floor, is such as to prevent the formation of bed sores. The cast is removed after 6-8 weeks, depending on age, when radiographs constantly confirm sound union. No further splintage, such as the use of a caliper, is ever indicated in this group of patients. Physiotherapy is also redundant since the child quickly becomes ambulant using the furniture as a support and when reviewed at hospital after a short period the restoration of function is normally complete. As Blount (1955) stated 'physiotherapy gilds the lily'. To avoid unnecessary visits the patient is then usually discharged, only a few with any degree of shortening (Fig. 5) being followed up for some months to watch the progress of growth of the injured limbs.

\section{Complications}

\section{(1) Vascular impairment}

Although there was no instance of vascular impairment in this series the complication is well recognized. Thomson \& Mahoney (1951) reported 
nine instances in 1233 fractures of the femur in children giving rise to Volkmann's ischaemic contracture. Most of them occurred after violent traffic accidents. The responsible fractures were usually in the upper part of the shaft and the first symptom was pain in the calf. Elevation of the limbs for Bryant's traction in the presence of surgical shock was considered to be a factor. Hall (1961) also referred to vascular complications in these injuries. Most of his patients were treated on a Thomas's splint and he recommended immediate release of the traction followed by sympathetic block if required, and occasionally exploration of the femoral artery.

\section{(2) Pressure sores}

There were no pressure sores either as the result of traction or from immobilization in a plaster cast in the series described here.

\section{(3) Residual deformity}

Remodelling of the femur to the extent that there is no residual bowing or thickening is a constant finding in children younger than 8 or 9 years as pointed out by Dameron \& Thompson (1959). Lateral angulation is more to be avoided than bowing in the antero-posterior direction. Overgrowth of the bone has been discussed above. Cole (1922), Burdick \& Siris (1923) and David (1924) stated that in the majority of patients any shortening was overcome. Aitken, Blackett \& Cincotti (1939) found that in children younger than 13 years in whom the normal length of the bone was restored at the time of reduction the average overgrowth was $1 \mathrm{~cm}$. The increase in length was greater when there was over-riding or when 'extreme bowing' persisted so that excessive callus was formed causing a longer period of hyperaemia. Blount (1955) agreed that excessive callus was a factor causing more overgrowth but he also referred to the amount of initial displacement of the fracture, and if remanipulation were done after callus had formed. In the femur illustrated in Fig. 5 a shortening of $1 \frac{1}{4}$ in. was overcome in 12 months. The present writer agrees with Blount (1955) that in children in the age-group considered in this series half an inch of shortening should be the aim at reduction, although oblique and spiral fractures seem to overgrow less than transverse fractures, and in undisplaced fractures (with intact periosteum) no discrepancy develops.

\section{Acknowledgment}

I should like to pay tribute to Sister L. Mawson for her devoted nursing care of all the children referred to in this paper.

\section{References}

Aitken, A.P., Blackett, C W. \& Cincotti, J.J. (1939) Overgrowth of the femoral shaft following fractures in childhood. J. Bone Jt Surg. 21, 334.

BLOCH, R. (1922) Les fractures de cuisse chez l'enfant. Revue d'Orthop. Serie 3, ix, 447.

BLOUNT, W.P. (1955) Fractures in children, Chapter VII. p. 129. Williams \& Wilkins, Baltimore.

Bryant, T. (1876) The Practice of Surgery, Vol. 2, p. 405. Churchill, London.

Burdick, C. G. \& SiRIs, I.E. (1923) Fractures of the femur in children. Ann. Surg. 77, 736.

Burwell, H.N. \& Charnley, A.D. (1964). Treatment of forearm fractures with particular reference to plate fixation. J. Bone Jt Surg. 46B, 404.

Clark, W.A. (1926) Fractures of the femur in children. J. Bone Jt Surg. 8, 273.

Cole, W.H. (1922) Results of treatment of fractured femurs in children. Arch. Surg. 5, 702.

Conwell, H.E. (1929) Acute fractures of the shaft of the femur in children. J. Bone Jt Surg. 11, 593.

Cushing, H. (1898) Quoted by Dameron, J.R. \& Thompson, H.A. (1959) Femoral shaft fractures in children. J. Bone Jt Surg. 41A, 1201.

Dameron, J.R. \& Thompson, H.A. (1959) Femoral shaft fractures in children. J. Bone Jt Surg. 41A, 1201.

DAvid, V.C. (1924) Shortening and compensatory overgrowth following fractures of the femur in children. Arch. Surg. 9, 438.

DeRIAN, P.S. \& Thompson, W.B. (1962) The management of lower extremity fractures in children. J. Bone Jt Surg. 44A, 803.

EIKENBARY, C.F. \& LeCocQ, J.F. (1932) Fractures of the femur in children. J. Bone Jt Surg. 14, 801.

HaLl, J.E. (1961) Meeting of 'The Little Orthopaedic Club' at Toronto General Hospital 1961. J. Bone Jt Surg. 44A, 206.

JoHnston, L.B. (1925) The treatment of fractures of the shaft of the femur in children. Arch. Surg. 10, 730.

KIDNER, F.C. \& LAKoff, C.B. (1922) Muscle interposition: a cause of delayed union in fractures of the femur. $J$. Amer. med. Ass. 79, 200.

Russell, R.H. (1924) Fractures of the femur: a clinical study. Brit. J. Surg. 11, 491.

SPEED, K. (1921) Analysis of the results of the treatment of fractures of the femoral diaphysis in children under 12 years of age. Surg. Gynaec. Obstet. 32, 527.

THOMSON, S.A. \& MAHONEY, L.J. (1951) Volkmann's ischaemic contracture: relationship to fracture of the femur. J. Bone Jt Surg. 33B, 336. 